\title{
AVALIAÇÃO DO DESEMPENHO DOS SISTEMAS GPS E GLONASS NO POSICIONAMENTO POR PONTO PRECISO, COMBINADOS E INDIVIDUALMENTE.
}

\author{
Performance evaluation of GPS and GLONASS systems, combined and \\ individually, in precise point positioning.
}

\author{
Bruno Guimarães Ventorim ${ }^{1}$ \\ William Rodrigo Dal Poz ${ }^{1}$ \\ 1 Universidade Federal de Viçosa - UFV.Programa de Pós-graduação em Engenharia Civil - \\ Informações Espaciais.- Viçosa - Minas Gerais - Brasil. Email:bruno.ventorim@ufv.br, \\ william.dalpoz@ufv.br\}
}

\section{Resumo:}

Este trabalho visa avaliar o desempenho dos sistemas GLONASS (Global'naya Navigatsionnay Sputnikovaya Sistema), GPS (Global Positioning System) e o uso combinado de ambos sistemas em diferentes latitudes, utilizando o serviço de Posicionamento por Ponto Preciso CSRS-PPP. Para isso foram selecionadas 16 estações da rede IGS (International GNSS Service), das quais foram utilizados os dados GNSS no formato RINEX do mês de agosto de 2014 e editados no TEQC (Translation, Editing, and Quality Check), obtendo arquivos com intervalos de 30 e 45 minutos, contendo apenas dados GPS, dados GLONASS e dados dos dois sistemas. As coordenadas estimadas no CSRS-PPP foram comparadas com as coordenadas de referência obtidas no sítio do ITRF (International Terrestrial Reference Frame), possibilitando o cálculo da acurácia do PPP com uso de dados GPS e GLONASS, separadamente e em conjunto. Após o cálculo das acurácias para cada dia de agosto, outliers foram detectados e eliminados utilizando o método boxplot com o uso do programa R. Verificou-se que o uso combinado do GPS e GLONASS, para todos as estações, proporcionou resultados mais acurados. Além disso, pode-se destacar a potencialidade do GLONASS, que apresentou desempenho superior ao do GPS na maioria das estações.

Palavras-chave: GPS, GLONASS, Integração GPS/GLONASS, PPP

\begin{abstract}
:
The aim of this paper is to analyse the performance of the GLONASS (Global'naya Navigatsionnay Sputnikovaya Sistema), GPS (Global Positioning System) and the combined use of both systems at different latitudes, by using the service Precise Point Positioning CSRS-PPP. For this purpose, 16 stations from the IGS (International GNSS Service) network were selected, from which were used the GNSS data in RINEX format of August 2014 and edited by using TEQC (Translation, Editing and Quality Check) to obtain files with intervals of 30 and 45
\end{abstract}


minutes, which only contain GPS data, GLONASS data and both systems data. The estimated coordinates in CSRS-PPP were compared with the reference coordinates obtained from the site of ITRF (International Terrestrial Reference Frame), enabling the accuracy calculation of the PPP by using GPS and GLONASS data, separated and combined. After the accuracies calculation for each day of august, outliers were detected and discarded by using boxplot method with the R software. It was found that GPS and GLONASS when used jointly, for all the stations, have enabled more accurate results. In addition, one may noticed the GLONASS potentiality, which presented superior performance when compared to GPS in most stations.

Keywords: GPS, GLONASS, Integration GPS/GLONASS, PPP

\section{Introdução}

Dentre os métodos de posicionamento GNSS (Global Navigation Satellite System), o PPP (Posicionamento por Ponto Preciso) tem se destacado e sido alvo de diversas pesquisas. O PPP faz uso das órbitas e correções precisas dos relógios dos satélites, disponível pelo IGS (International GNSS Service) (Seeber 2003). Requer também, para que se alcance alta acurácia, que a maioria das fontes de erros seja tratada, como os efeitos relacionados aos satélites, ao receptor, à carga oceânica, aos atrasos ionosféricos e troposféricos, à relatividade, dentre outros (Cai e Gao 2013).

Ao longo das duas últimas décadas, o uso de observações de receptores de dupla frequência no PPP tem sido extensivamente pesquisado, e vários serviços online de PPP foram desenvolvidos, comprovando que o posicionamento por ponto a nível centimétrico não só é possível no modo estático pós-processado, mas potencialmente também para aplicações em tempo real, com um único receptor GNSS(Grinter e Roberts 2011).

Atualmente, duas instituições disponibilizam o serviço de posicionamento online PPP que são capazes de processar dados GNSS coletados pelo GLONASS e GPS: o CSRS-PPP (Canadian Spatial Reference System) e o MagicGNSS-PPP (GMV 2015). O serviço de posicionamento online PPP disponibilizados pelo IBGE (Instituto Brasileiro de Geografia e Estatística), denominado de IBGE-PPP, também processa dados coletados pelo GPS e GLONASS. Porém, o IBGE-PPP usa o mesmo aplicativo do CSRS-PPP, desenvolvido pelo NRCan (Geodetic Survey Division of Natural Resources os Canada) (IBGE 2013).

O GLONASS enfrentou uma crise em 1996, com isso, o número de satélites operacionais da sua constelação havia reduzido significativamente. Em 2004 foi lançado um programa de modernização com novos investimentos e lançamento de novos satélites (Monico 2008). Entretanto, desde outubro de 2011, o GLONASS foi considerado completamente operacional, visto que a constelação do GLONASS atingiu o número nominal de satélites, que consiste de um total de 24 satélites operacionais (Gibbons, Divis, e Gutierrez 2013). Diante do exposto, trata-se de um momento oportuno para a realização de pesquisas relacionadas com a integração entre o GLONASS e o GPS no PPP online.

Destaca-se que alguns trabalhos sobre a integração entre o GPS e o GLONASS, como por exemplo os trabalhos realizados por Cai e Gao (2007), Ferrão (2013), Farah (2014), Vaz, Pissardini, Fonseca Junior (2013) e Jerez et al. (2014), apresentaram resultados discordantes no que diz respeito à melhora proporcionada pela integração entre o GPS e o GLONASS no PPP. 
Cai e Gao (2007) avaliaram a integração GPS e GLONASS utilizando PPP, comparando o processamento com dados apenas GPS e com dados dos dois sistemas. Devido a constelação GLONASS apresentar poucos satélites na ocasião, não foi possível realizar o processamento individal desse sistema, visto que na maior parte do tempo apenas 2 ou 3 satélites eram visíveis. Verificou-se que, embora tenha melhorado a acurácia do posicionamento, o GLONASS não causou impacto significativo nos resultados.

Ferrão (2013) faz a análise da integração dos sistemas GPS e GLONASS no PPP e verificou que a integração traz melhoras significativas ao posicionamento quando comparado com os processamentos individuais dos sistemas, se sobressaindo mais ainda em relação ao GLONASS. No trabalho de Farah (2014), chega-se a uma conclusão semelhante, porém a análise é feita também para intervalos curtos. Entretanto, nesses trabalhos a avaliação é feita apenas para um dia referente a uma estação somente.

Vaz, Pissardini e Fonseca Junior (2013) fizeram uma análise de uma série temporal com os 200 primeiros dias do ano de 2012 de rastreio de uma estação pertencente à RBMC (Rede Brasileira de Monitoramento Contínuo). Foi verificado que ambos sistemas possuem disponibilidade de dados semelhantes, entretando o GPS, em 95\% das épocas, apresenta número maior de sátelites. Utilizando MagicGNSS-PPP para a análise da acurácia dos sistemas individualmente e combinados, verificaram que o GPS apresentou resultados melhores em relação ao GLONASS e à combinação dos sistemas.

Jerez et al. (2014), fizeram uma análise do processamento em dois diferentes intervalos de rastreio, um curto (20 minutos) e um longo ( 24 horas), para o PPP e para o posicionamento relativo, com dados GPS, GLONASS e combinados durante 10 dias. Com relação ao PPP, os autores não observaram melhoria com o uso combinado na maior parte dos dias, indicando que seria necessária uma análise com mais dias de processamento para pequenos intervalos de tempo. Em 24 horas não houve mudança significativa nos resultados, obtendo diferenças milimétricas.

É importante destacar que os trabalhos realizados por Ferrão (2013), Farah (2014), Vaz, Pissardini e Fonseca Junior (2013) e Jerez et al. (2014) apresentaram resultados discordantes no que diz respeito à melhora proporcionada pela integração entre o GPS e o GLONASS no PPP. Desta forma, este trabalho também se justifica pela continuação de trabalhos desta natureza, objetivando analisar se a integração entre o GPS e o GLONASS proporciona de fato resultados mais acurados.

Este trabalho tem como objetivo analisar o desempenho do GPS e GLONASS, combinados e individualmente no PPP, por meio do serviço de posicionamento online CSRS-PPP. Para isso, foram utilizados dados GNSS de 16 estações da rede IGS, abrangendo 31 dias de cada estação, em dois intervalos curtos de rastreio (30 e 45 minutos).

\section{Similaridades e Diferenças entre GPS e o GLONASS}

Como ambos os sistemas de posicionamento global tem os mesmos propósitos, inevitavelmente, apresentam algumas similaridades. Além disso, os sistemas também apresentam algumas diferenças, que por sua vez, tem impacto direto na integração do PPP. As principais diferenças 
consistem basicamente nas características dos sinais, nos sistemas de referência e nos sistemas de tempo.

A Tabela 1 sumariza uma comparação entre o GPS e o GLONASS, entretanto, não considera o processo de modernização dos sistemas.

Tabela 1 - Comparação GPS e GLONASS. Fonte: adaptado de (Cai 2009).

\begin{tabular}{|l|c|c|}
\cline { 2 - 3 } \multicolumn{1}{l|}{} & GLONASS & GPS \\
\hline Número de satélites & 24 & 24 \\
\hline $\begin{array}{l}\text { Número de planos } \\
\text { orbitais }\end{array}$ & 3 & 6 \\
\hline $\begin{array}{l}\text { Inclinação da órbita } \\
\text { Identificação dos } \\
\text { satélites }\end{array}$ & FDMA & $55^{\circ}$ \\
\hline $\begin{array}{l}\text { Frequência da onda } \\
\text { portadora }\end{array}$ & $\begin{array}{c}\text { 1602+k*0.5625 MHz } \\
1246+\mathrm{k}^{*} 0.4375 \mathrm{MHz}\end{array}$ & $\begin{array}{c}12275.42 \mathrm{MHz} \\
122.60 \mathrm{MHz}\end{array}$ \\
\hline $\begin{array}{l}\text { Frequência do código } \\
\text { (MHz) }\end{array}$ & C/A code : 0.511 & C/A code: 1.023 \\
\hline $\begin{array}{l}\text { Sistema de referência } \\
\text { Pistema de tempo }: 5.11\end{array}$ & P code: 10.23 \\
\hline
\end{tabular}

Ressalta-se que os novos satélites GLONASS-K transmitirão sinais CDMA (Code Division Multiple Access) na banda L3, inaugurando uma nova era para o sistema Russo, pois facilitará a interoperabilidade com outros componentes GNSS (Urlichich et al. 2011). O GPS faz uso da técnica CDMA, em que o satélite é identificado pelo código transmitido, enquanto o GLONASS faz uso da técnica FDMA (Frequency Division Multiple Access), que identifica cada satélite pela frequência transmitida (Hofmann-Wellenhof, Lichtenegger, e Wasle 2008). Interoperabilidade é um conceito importante no GNSS, que pode ser definida como a capacidade de usar dois serviços em conjunto para conseguir melhor performance ao nível do usuário (Whitehouse 2004).

De acordo com a Tabela 1, para a frequência do GLONASS aparece o valor k, que é o número inteiro que diferencia os canais de frequência de cada satélite. Inicialmente eram 24 valores de k, um para cada satélite, entretanto após 2005, os satélites têm transmitido em 12 canais de frequência, onde os satélites em posição antipodal dentro do mesmo plano orbital podem ter o mesmo número de canal. O número k varia de -7 à +6 (Hofmann-Wellenhof, Lichtenegger, e Wasle 2008).

Para fins de navegação, os sistemas geodésicos de referencia adotados pelos sistemas são diferentes. O GPS utiliza o WGS84 (World Geodetic System 1984), enquanto o GLONASS faz uso do PZ-90 (Parametry Zemli 1990). Os dois são sistemas geocêntricos bem similares, porém existem pequenas diferenças expressas por rotações, translações e escala (Lago, Ferreira, e Krueger 2002). Na integração dos sistemas GPS e GLONASS esse fator só é importante ao utilizar as efemérides transmitidas por ambos os sistemas. Para o PPP são utilizadas efemérides precisas referentes aos dois sistemas, que já são calculadas no mesmo sistema de referencia, o IGb08. Ao nível global, as realizações ITRF2008, e IGb08 são equivalentes, no sentido de que eles compartilham a mesma origem, escala e orientação (Bruyninx et al. 2013). Em outras palavras, atualmente, como qualquer outro sistema de posicionamento online PPP que utiliza 
somente dados GPS, os sistemas que consideram a integração também estimarão as coordenadas em IGb08.

No PPP o aspecto mais importante com relação às diferenças entre os sistemas se refere ao sistema de tempo que cada sistema adota. Ambos estão ligados ao próprio sistema de tempo independentes, que estão referenciados à diferentes realizações do UTC (Universal Time Coordinated). Esta é a principal diferença que deve ser considerada na integração entre o GPS e o GLONASS no PPP.

Com uso de dados de duas portadoras pode-se aplicar a combinação linear livre dos efeitos da ionosfera. Com isso, os efeitos de primeira ordem da ionosfera são removidos. Além disso, com o uso de efemérides precisas (GPS e GLONASS) disponibilizadas pelo IGS, os efeitos de órbita e dos relógios dos satélites são negligenciáveis. Desta forma, as expressões matemáticas referentes às observações de código e fase, para o GPS e GLONASS, são dadas pelas Equações de 01 a 04:

$$
\begin{aligned}
& P_{I F}^{G}=\rho_{G}+c d t^{G}+d_{\text {trop }}^{G}+\varepsilon_{P_{I F}}^{G} \\
& \phi_{I F}^{G}=\rho_{G}+c d t^{G}+d_{\text {trop }}^{G}+N_{I F}^{G}+\varepsilon_{\phi_{I F}}^{G} \\
& P_{I F}^{R}=\rho_{R}+c d t^{R}+d_{\text {trop }}^{R}+\varepsilon_{P_{I F}^{R}}^{R} \\
& \phi_{I F}^{R}=\rho_{R}+c d t^{R}+d_{\text {trop }}^{R}+N_{I F}^{R}+\varepsilon_{\phi_{I F}}^{R}
\end{aligned}
$$

Os índices G e R se referem a observações coletadas pelo GPS e GLONASS, respectivamente. $P_{I F}$ e $\phi_{I F}$ são as combinações lineares livres dos efeitos da ionosfera para o código e para a fase, respectivamente, e $\rho$ representa a distância geométrica entre o receptor e os satélites. O termo c se refere a velocidade da luz no vácuo, dt representa o erro do relógio do receptor (com relação aos sistemas de tempo GPS e GLONASS), $d_{\text {trop }}$ se refere ao atraso troposférico, que independe da frequência, $N_{I F}$ se refere a ambiguidade resultante da combinação linear, e $\varepsilon_{P_{I F}}$ e $\varepsilon_{\phi_{I F}}$ representam os efeitos aleatórios, efeitos sistemáticos não modelados e ruído da combinação linear livre dos efeitos da ionosfera, para o código e fase, respectivamente. Os termos referentes as tendências interferências referentes ao receptor e satélites não são considerados nas expressões apresentadas. Maiores detalhes podem ser encontrados em Cai (2009).

O erro do relógio do receptor com relação ao sistema de tempo GLONASS pode ser descrito pela soma do erro do relógio do receptor com relação ao tempo GPS e a diferença entre os sistemas de tempo GLONASS e GPS, dado por (Cai e Gao 2007; Cai 2009) expresso na Equação 5:

$$
d t^{R}=d t^{G}+c d t_{S I S}
$$

Sendo $d t_{S I S}$ a diferença entre os sistemas de tempo GLONASS e GPS. Desta forma, reescrevendo as Equações 1 a 4, tem-se as Equações 6, 7, 8 e 9:

$$
\begin{aligned}
& P_{I F}^{G}=\rho_{G}+c d t^{G}+d_{\text {trop }}^{G}+\varepsilon_{P_{I F}}^{G} \\
& \phi_{I F}^{G}=\rho_{G}+c d t^{G}+d_{\text {trop }}^{G}+N_{I F}^{G}+\varepsilon_{P_{F F}}^{G} \\
& P_{I F}^{R}=\rho_{R}+c d t^{G}+c d t_{S I S}+d_{\text {trop }}^{R}+\varepsilon_{P_{I F}^{R}}^{R} \\
& \phi_{I F}^{R}=\rho_{R}+c d t^{G}+c d t_{S I S}+d_{\text {trop }}^{R}+N_{I F}^{R}+\varepsilon_{P_{I F}}^{R}
\end{aligned}
$$

Bol. Ciênc. Geod., sec. Artigos, Curitiba, v. 22, no2, p.264 - 281, abr - jun, 2016. 
As Equações 6, 7, 8 e 9 representam o modelo de observação tradicional para a integração entre o GPS e o GLONASS no PPP. A principal desvantagem do PPP se refere ao tempo de convergência (conhecido na literatura inglesa como warm-up time ou como convergence timelconvergence period) necessário para a melhora progressiva da acurácia posicional (Martin 2013). Espera-se que com observações adicionais de satélites GLONASS este tempo seja menor, em função da melhora da geometria. Além disso, este tempo depende também do local onde o receptor foi instalado, da qualidade da observação e do intervalo de coleta dos dados GNSS (Cai 2009).

\section{Metodologia}

Para este trabalho foram utilizados dados GNSS de 16 estações da rede IGS, que foram préselecionadas para que ficassem espaçadas em intervalos aproximadamente regulares de latitude, além de coletarem dados dos dois sistemas de posicionamento, GPS e GLONASS. Para realizar uma análise temporal, foram obtidos dados de 31 dias, referentes ao mês de agosto de 2014. A Tabela 2 lista as estações selecionadas e suas respectivas latitudes aproximadas.

Tabela 2 - Lista de estações selecionadas e suas latitudes aproximadas.

\begin{tabular}{c|c|c|c}
\hline Estação & $\begin{array}{c}\text { Latitude } \\
\text { Aproximada } \\
(\mathbf{(})\end{array}$ & Estação & $\begin{array}{c}\text { Latitude } \\
\text { Aproximada } \\
(\mathbf{O})\end{array}$ \\
\hline SYOG & -69.01 & KOUR & 5.25 \\
OHI2 & -63.32 & PIMO & 14.64 \\
MAC1 & -54.5 & MAS1 & 27.76 \\
HOB2 & -42.8 & PDEL & 37.75 \\
SUTM & -32.38 & STJO & 47.59 \\
CHPI & -22.69 & ONSA & 57.4 \\
BRAZ & -15.95 & KIRU & 67.86 \\
MBAR & -0.6 & THU3 & 76.54
\end{tabular}

Antes do processamento, cada arquivo RINEX foi editado com o software TEQC (Translation, Editing, and Quality Check) da UNAVCO, com o objetivo de gerar três arquivos, resultantes do arquivo original: um arquivo RINEX com dados GPS, outro com dados GLONASS e outro com dados dos dois sistemas. Para cada um desses arquivos, foram gerados mais dois, contendo dados com 30 e 45 minutos de rastreio, contados a partir das 12h TUC. Desta forma, ao todo, foram gerados 2976 arquivos [31(dias) x 16(estações) x 3(GPS, GLONASS e GPS/GLONASS) x 2 (30 e 45 minutos $)=2976$ ], ou seja, foram realizados 2976 processamentos.

Após a edição dos arquivos, os mesmos foram processados no serviço de processamento on-line CSRS-PPP. O serviço CSRS-PPP processa os dados e envia um e-mail com os arquivos de processamento que contém, dentre diversas informações sobre o processamento, as coordenadas cartesianas e os respectivos desvios padrão no sistema de referência ITRF2008 (IGb08) na época em que os dados foram coletados.

No processamento dos dados, o CSRS-PPP aplica a combinação linear livre dos efeitos da ionosfera (todos os receptores da rede IGS são de dupla frequência), permitindo a eliminação dos efeitos de primeira ordem da ionosfera, máscara de elevação de $10^{\circ}$ e fez uso de efemérides 
precisas finais, objetivando a minimização dos erros orbitais. Além disso, o efeito da troposfera é minimizado com o uso dos modelos de Davis e Hopfield, aplicando a função de mapeamento global (GMF - Global Mapping Function). Efeitos da carga oceânica também são considerados no CSRS-PPP, em locais até $10 \mathrm{~km}$ da costa (corrigidos utilizando o modelo FES2004) e os desvios e variações do centro de fase das antenas (corrigidos por arquivos disponibilizados pelo IGS e pelo NGS). Todas essas informações podem ser obtidas no arquivo com extensão *.sum que é fornecido pelo CSRS-PPP e também podem ser obtidas em IBGE (2013). Contudo, as correções de maré terrestre não são aplicadas. Efeitos de carga da pressão atmosférica são desprezíveis no PPP (Urquhart 2009). Salienta-se que o serviço de posicionamento online GAPS, desenvolvido pela UNB (University of New Brunswick) aplica a correção de maré terrestre, porém não processa dados GLONASS (UNB, 2015).

O intervalo de processamento dos dados é de 30 segundos, com exceção da estação BRAZ que foi de 15 segundos.

As coordenadas de referência foram obtidas pelo site <http://itrf.ensg.ign.fr/>. O sítio já fornece as coordenadas atualizadas para a época dos dados, logo foram obtidas coordenadas de referência para cada dia de cada estação, no sistema de referência ITRF2008(IGb08). Tem-se, portanto, coordenadas estimadas e de referência na mesma época e no mesmo referencial geodésico, sendo assim possível uma análise mais acurada.

A análise dos resultados foi realizada em coordenadas geodésicas curvilíneas. Porém, como as coordenadas obtidas do processamento e as de referência são coordenadas cartesianas, foi necessária a transformação das mesmas em coordenadas geodésicas de acordo com o método direto proposto por Bowring (1976). Para isso, foram utilizados os parâmetros do elipsoide GRS80.

Em seguida, com a matriz variância covariância das coordenadas cartesianas foram obtidas as precisões das coordenadas geodésicas via propagação de variância $\left(\sigma \phi_{m} \sigma \lambda_{m}\right)$.

Na sequência, foram então calculadas as discrepâncias da latitude e da longitude $\left(\Delta \phi_{\text {rad }}, \Delta \lambda_{\text {rad }}\right)$ utilizando as Equações 10 e 11:

$$
\begin{gathered}
\Delta \phi_{\text {rad }}=\left|\phi_{\text {cal }}-\phi_{\text {ref }}\right| \\
\Delta \lambda_{\text {rad }}=\left|\lambda_{\text {cal }}-\lambda_{\text {ref }}\right|
\end{gathered}
$$

Sendo $\phi_{\text {est }}$ e $\lambda_{\text {est }}$ as coordenadas estimadas pelo CSRS-PPP e $\phi_{\text {ref }}$ e $\lambda_{\text {ref }}$ as coordenadas de referência.

Note que as discrepâncias foram obtidas em radianos, tornando necessária a conversão para metros, utilizando as Equações 12 e 13 (Torge 2001):

$$
\begin{gathered}
\Delta \phi_{m}=M \Delta \phi_{\mathrm{rad}} \\
\Delta \lambda_{m}=M \Delta \lambda_{\mathrm{rad}} \cos \phi
\end{gathered}
$$

Sendo M o raio de curvatura da seção meridiana dada pela Equação 14:

$$
M=\frac{a\left(1-e^{2}\right)}{\left(1-e^{2} \operatorname{sen} \phi\right)^{3 / 2}}
$$

Para o cálculo das componentes planimétricas referentes à precisão $(\mathrm{P})$ e tendência $(\mathrm{T})$ foram utilizadas as Equações 15 e 16: 


$$
\begin{aligned}
& P=\sqrt{\left(\sigma \phi_{m}\right)^{2}+\left(\sigma \lambda_{m}\right)^{2}} \\
& T=\sqrt{\left(\Delta \phi_{m}\right)^{2}+\left(\Delta \lambda_{m}\right)^{2}}
\end{aligned}
$$

A partir das Equações 15 e 16 foram calculados os valores de acurácia planimétrica $\left(A_{\text {Plan }}\right)$, de acordo com a Equação 17, proposta por Gauss (Mikhail and Ackermann 1976):

$$
A_{\text {Plan }}=\sqrt{P^{2}+T^{2}}
$$

Feito todos os cálculos de acurácia para as componentes planimétricas de cada estação, foi observado que existem valores muito destoantes dos demais e por isso foi feito a detecção de outliers pelo método gráfico do boxplot utilizando o software livre R (R Core Team 2014).

\section{Resultados e análises}

Após a detecção e eliminação dos outliers nos valores de acurácia calculados, foram elaborados gráficos de radar, também denominados de gráficos de aranha. As Figuras de 1 à 6 mostram a variação temporal da acurácia planimétrica para todas as estações nos intervalos de 30 e 45 minutos. As latitudes das estações são identificadas nas figuras, bem como os dias do mês de agosto (1 a 31). A escala está em unidade métrica (escala igual a $1 \mathrm{~m}$ ). Na análise dos resultados serão utilizados os termos PPP-GPS, PPP-GLONASS e PPP-GPS/GLONASS. 
SYOG: Acurácia da Componente Planimétrica $30 \mathrm{~min}$

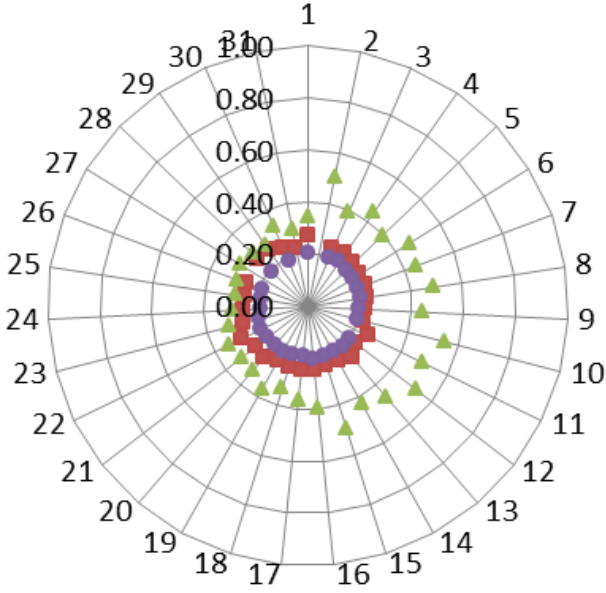

- GLONASS $\triangle$ GPS • GPSE GLONASS

OHI2: Acurácia da Componente Planimétrica 30min

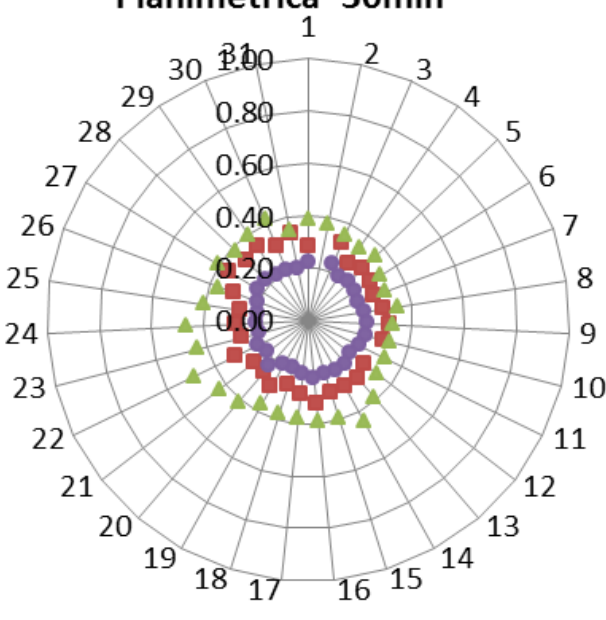

- GLONASS $\triangle$ GPS • GPS E GLONASS

MAC1: Acurácia da Componente Planimétrica $30 \mathrm{~min}$

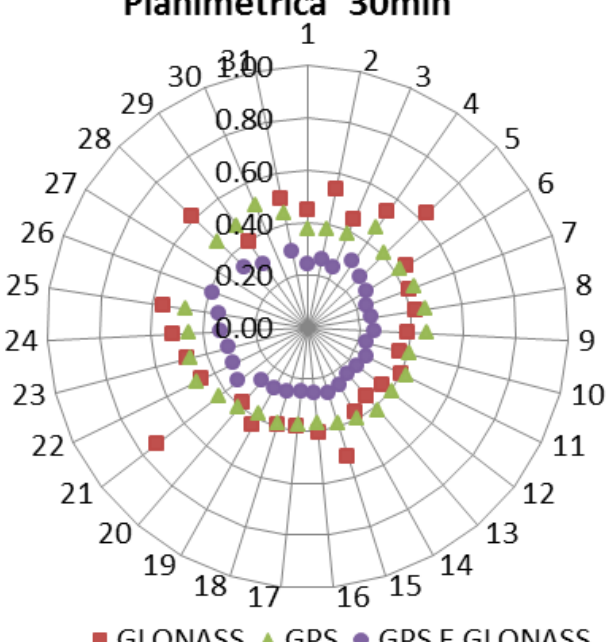

SYOG: Acurácia da Componente Planimétrica $45 \mathrm{~min}$

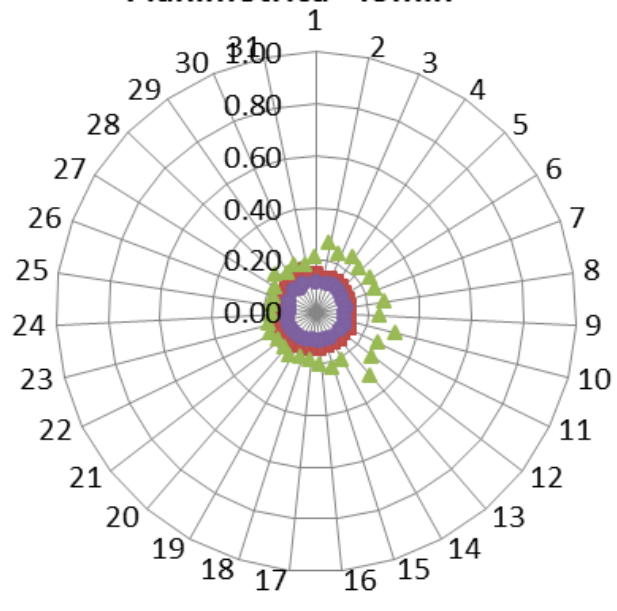

- GLONASS $\triangle$ GPS • GPSE GLONASS

\section{OHI2: Acurácia da Componente} Planimétrica $45 \mathrm{~min}$

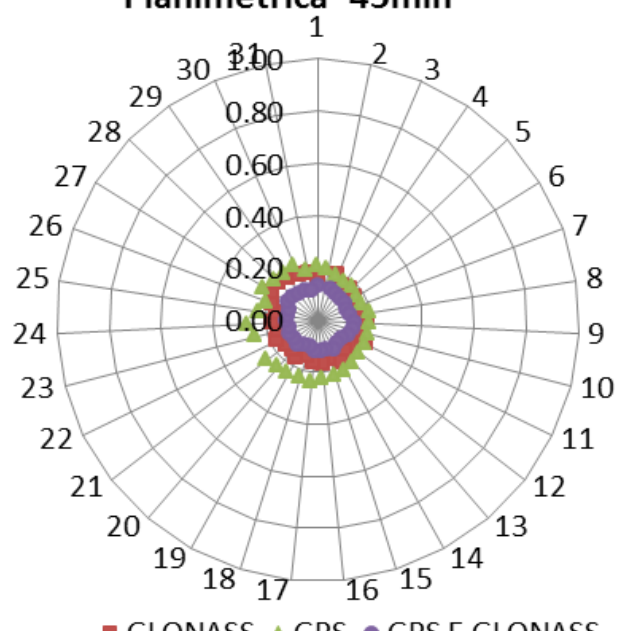

MAC1: Acurácia da Componente Planimétrica $45 \mathrm{~min}$

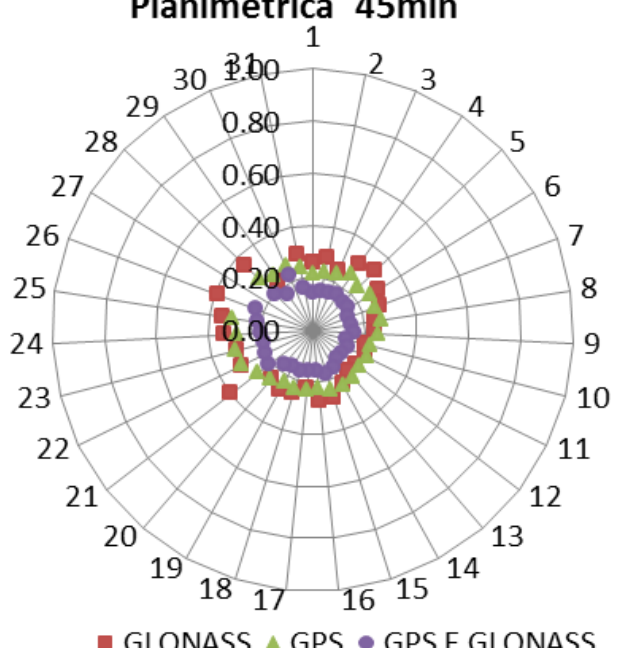

Figura 1 - Gráfico da variação temporal da acurácia planimétrica (m) das estações SYOG (lat: $69^{\circ}$ ), OHI2 (lat: $-63^{\circ}$ ) e MAC1 (lat: $-55^{\circ}$ ). 
HOB2: Acurácia da Componente Planimétrica $30 \mathrm{~min}$

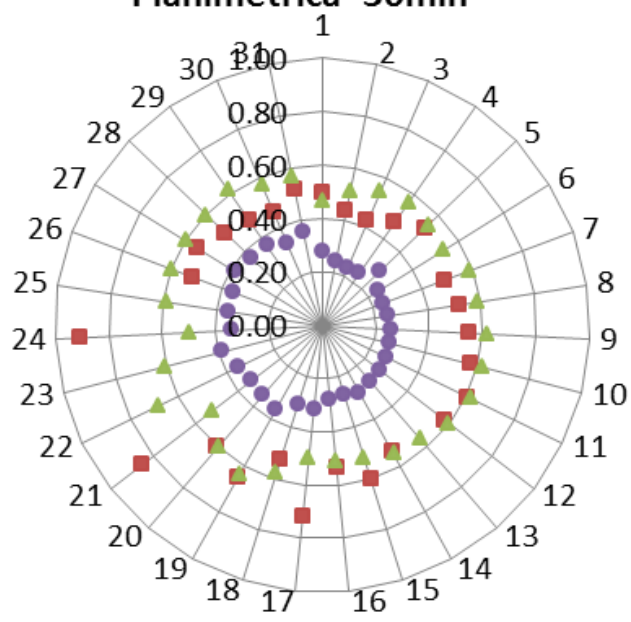

- GLONASS $\triangle$ GPS • GPS E GLONASS

\section{SUTM: Acurácia da Componente} Planimétrica $30 \mathrm{~min}$

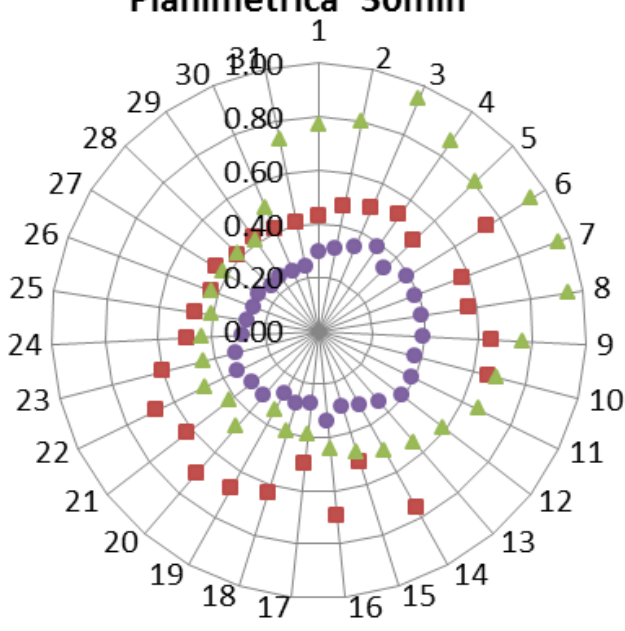

- GLONASS $\triangle$ GPS • GPS E GLONASS

\section{CHPI: Acurácia da Componente} Planimétrica $30 \mathrm{~min}$

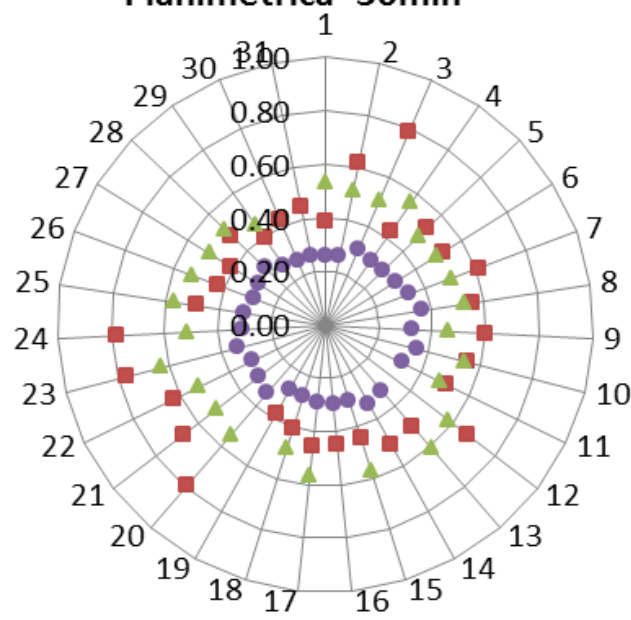

- GLONASS $\triangle$ GPS • GPS E GLONASS
HOB2: Acurácia da Componente Planimétrica $45 \mathrm{~min}$

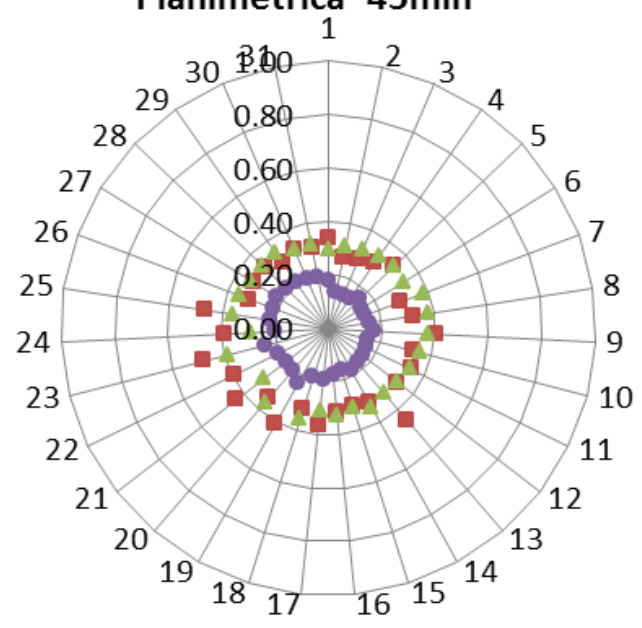

- GLONASS $\triangle$ GPS • GPS E GLONASS

SUTM: Acurácia da Componente Planimétrica $45 \mathrm{~min}$

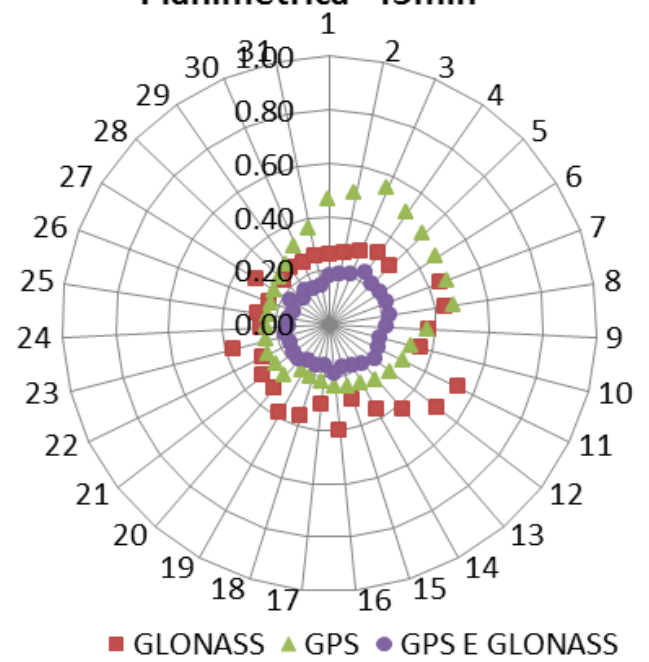

CHPI: Acurácia da Componente Planimétrica $45 \mathrm{~min}$

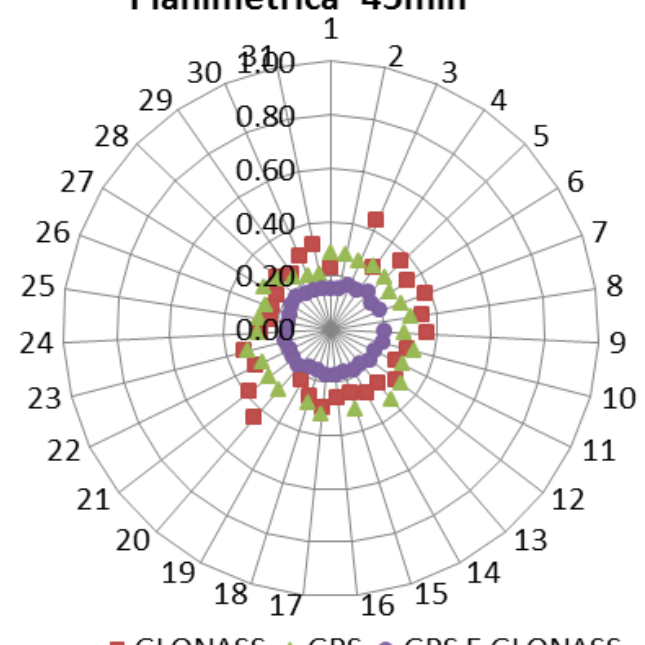

- GLONASS $\triangle$ GPS • GPS E GLONASS

Figura 2 - Gráfico da variação temporal da acurácia planimétrica (m) das estações HOB2 (lat: $43^{\circ}$ ), SUTM (lat: $-32^{\circ}$ ) e CHPI (lat: $-23^{\circ}$ ). 
BRAZ: Acurácia da Componente Planimétrica $30 \mathrm{~min}$

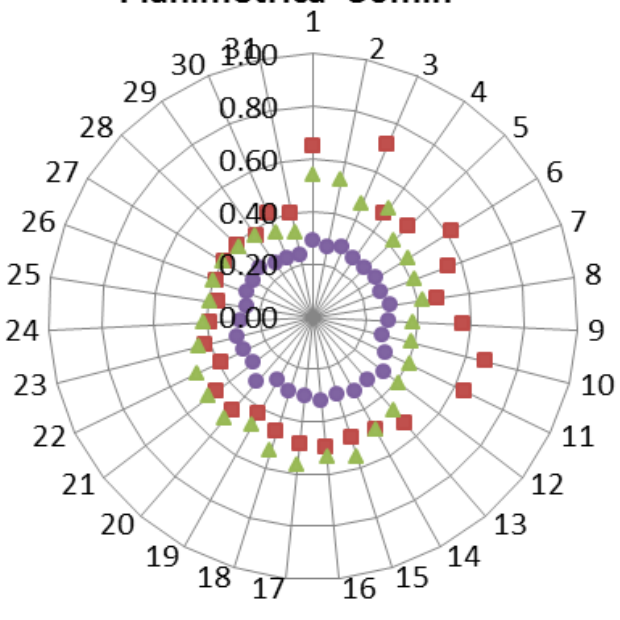

- GLONASS $\triangle$ GPS • GPS E GLONASS

MBAR: Acurácia da Componente Planimétrica $30 \mathrm{~min}$

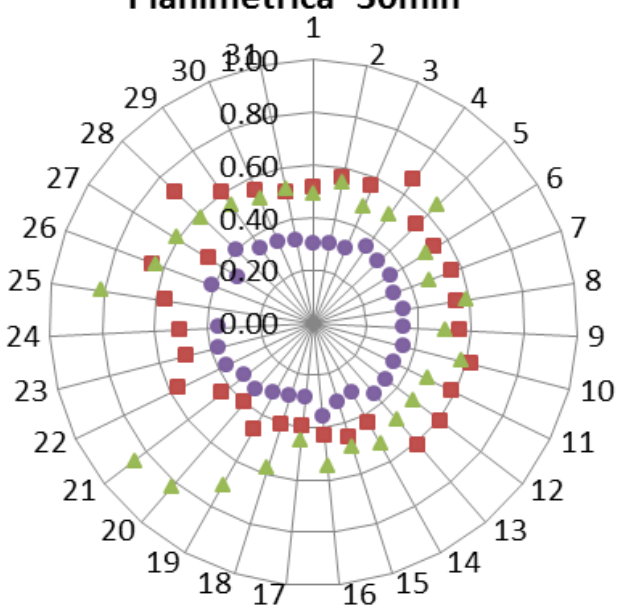

- GLONASS $\triangle$ GPS • GPS E GLONASS

KOUR: Acurácia da Componente Planimétrica 30min

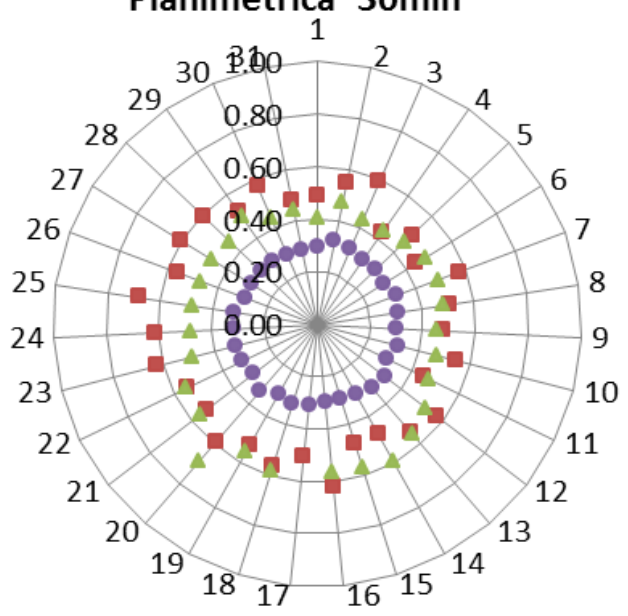

- GLONASS $\triangle$ GPS • GPS E GLONASS
BRAZ: Acurácia da Componente Planimétrica $45 \mathrm{~min}$

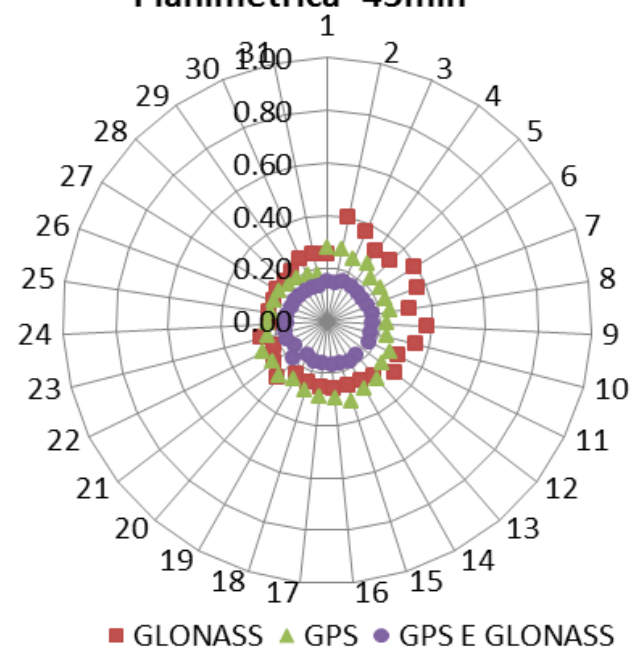

MBAR: Acurácia da Componente Planimétrica $45 \mathrm{~min}$

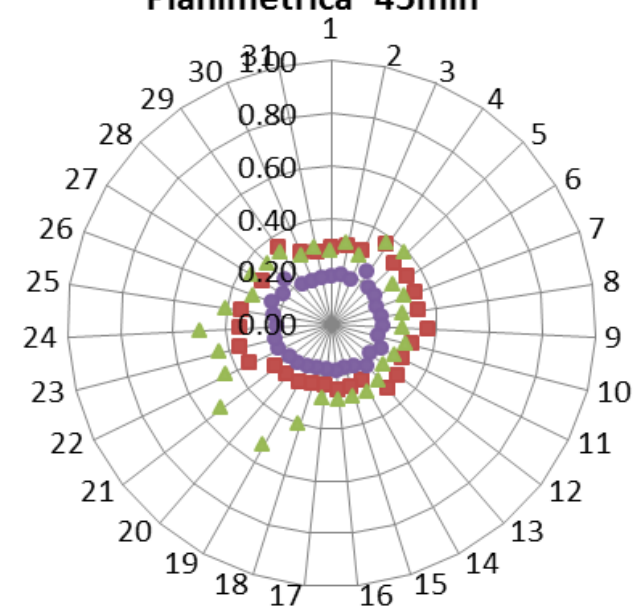

- GLONASS $\triangle$ GPS • GPS E GLONASS

\section{KOUR: Acurácia da Componente Planimétrica $45 \mathrm{~min}$}

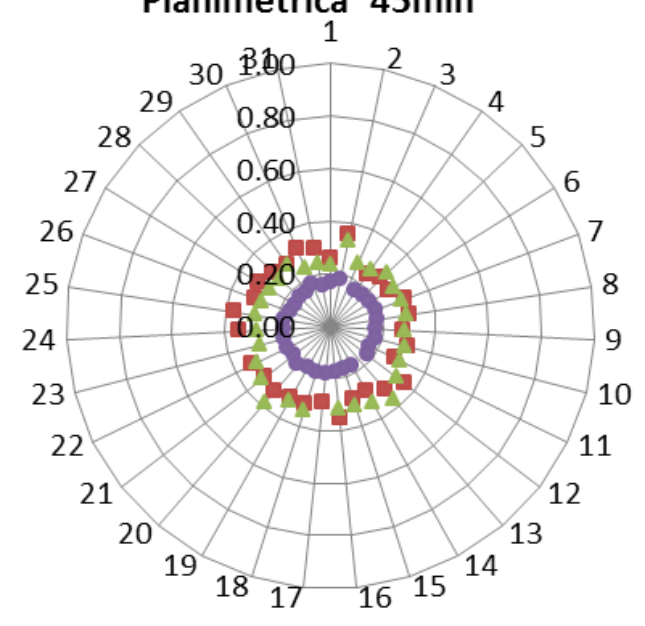

- GLONASS $\triangle \mathrm{GPS} \bullet$ GPS E GLONASS 
Figura 3 - Gráfico da variação temporal da acurácia planimétrica (m) das estações BRAZ (lat: $16^{\circ}$ ), MBAR (lat: $-01^{\circ}$ ) e KOUR (lat: $05^{\circ}$ ).

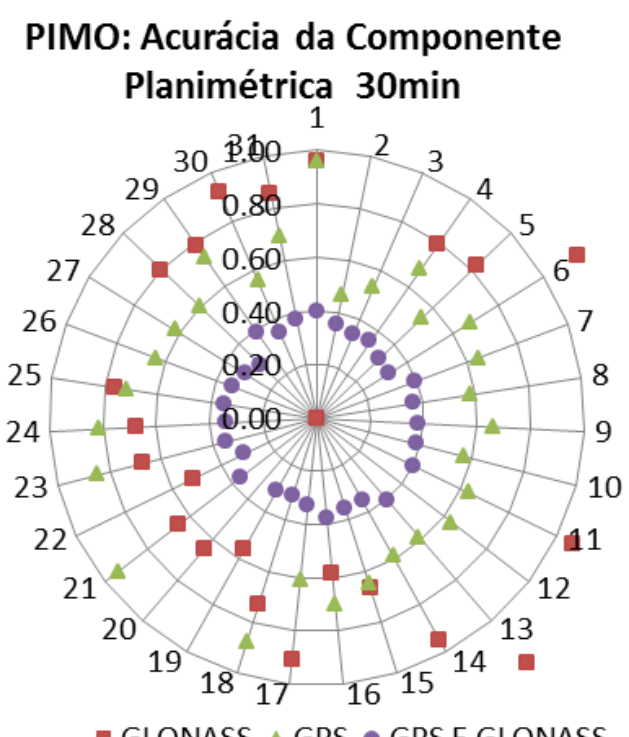

- GLONASS $\triangle$ GPS • GPS E GLONASS

\section{MAS1: Acurácia da Componente} Planimétrica $30 \mathrm{~min}$

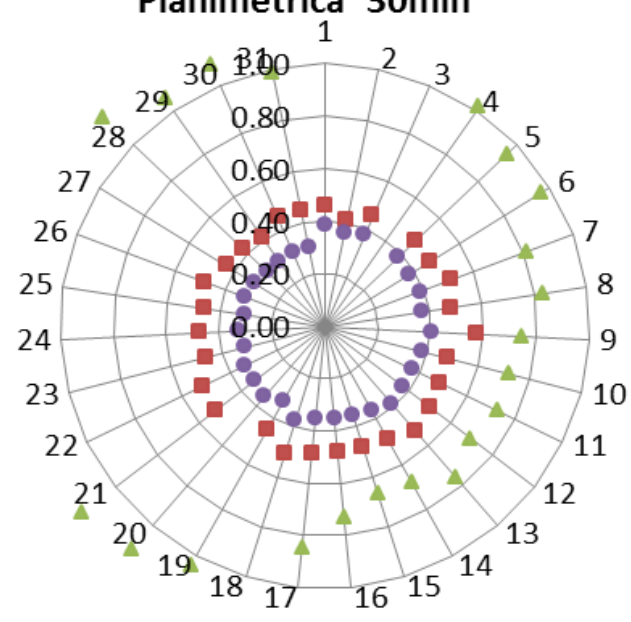

- GLONASS $\triangle \mathrm{GPS} \bullet \mathrm{GPSE}$ GLONASS

PDEL: Acurácia da Componente Planimétrica $30 \mathrm{~min}$

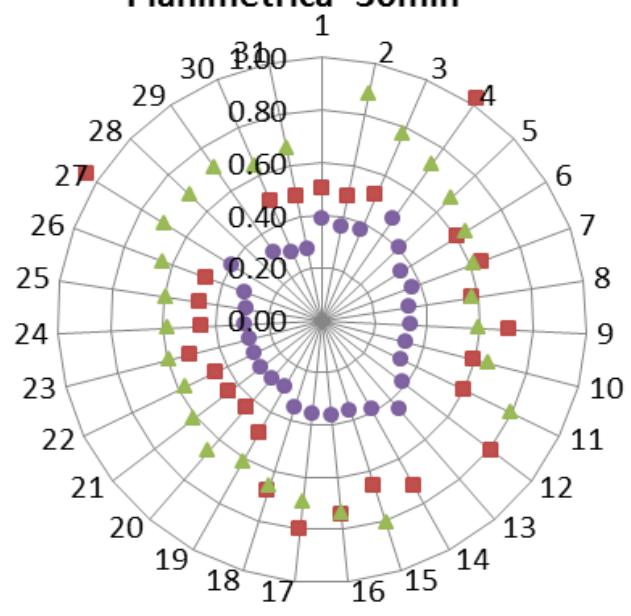

- GLONASS $\triangle \mathrm{GPS} \bullet \mathrm{GPSE}$ GLONASS

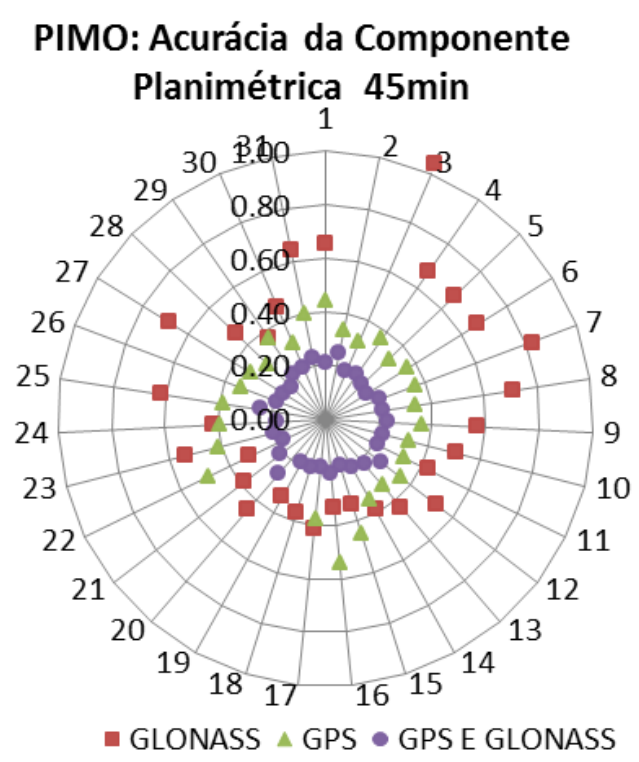

MAS1: Acurácia da Componente Planimétrica $45 \mathrm{~min}$

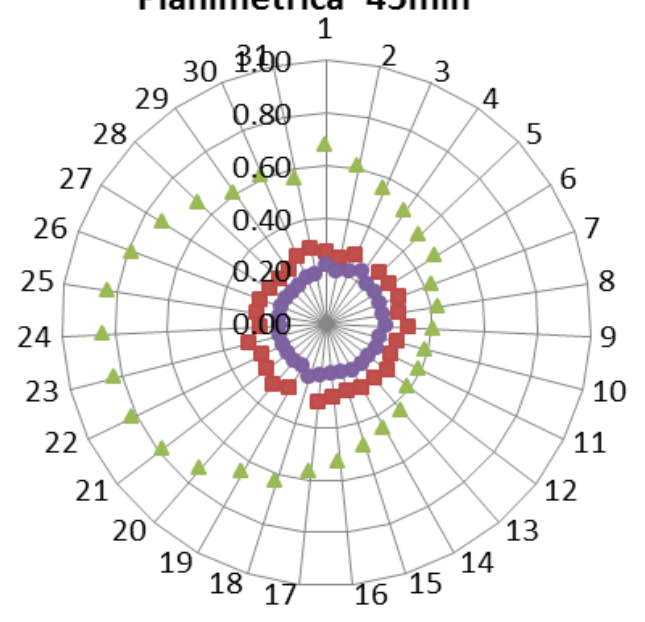

- GLONASS $\triangle$ GPS • GPSE GLONASS

PDEL: Acurácia da Componente Planimétrica $45 \mathrm{~min}$

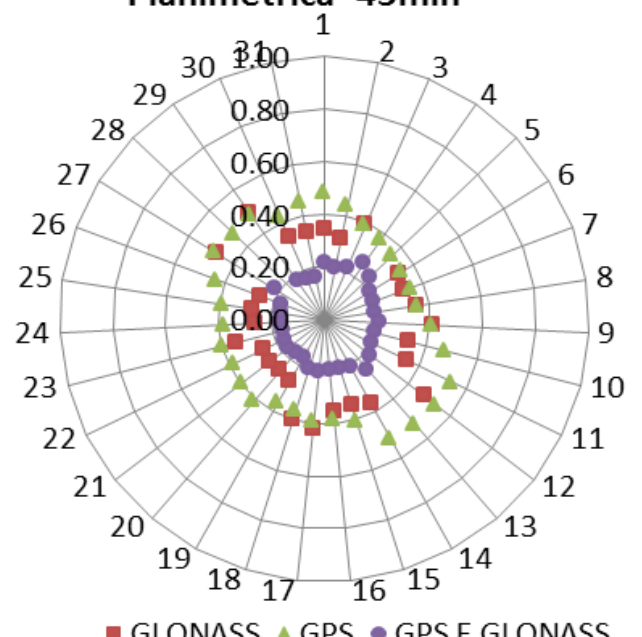

Bol. Ciênc. Geod., sec. Artigos, Curitiba, v. 22, no2, p.264 - 281, abr - jun, 2016. 
Figura 4 - Gráfico da variação temporal da acurácia planimétrica (m) das estações PIMO (lat: $15^{\circ}$ ), MAS1 (lat: $28^{\circ}$ ) e PDEL (lat: $38^{\circ}$ ).

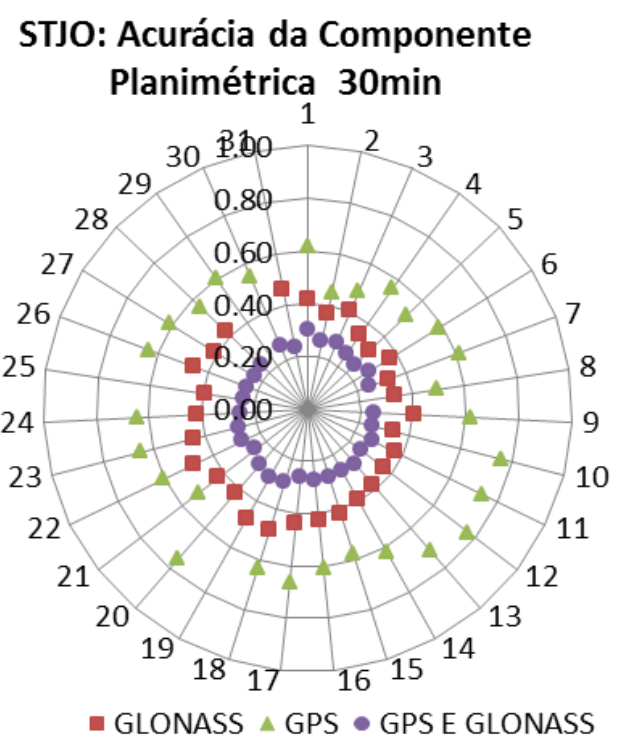

ONSA: Acurácia da Componente Planimétrica $30 \mathrm{~min}$

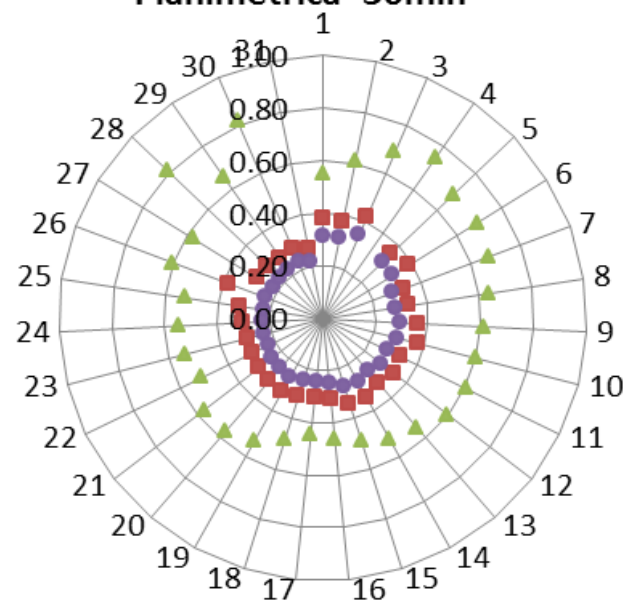

- GLONASS $\triangle$ GPS • GPS E GLONASS

KIRU: Acurácia da Componente Planimétrica 30min

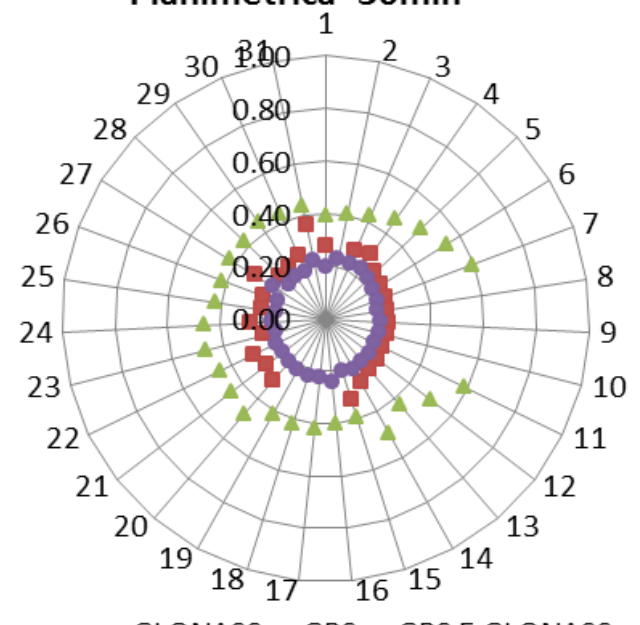

- GLONASS $\triangle$ GPS • GPS E GLONASS

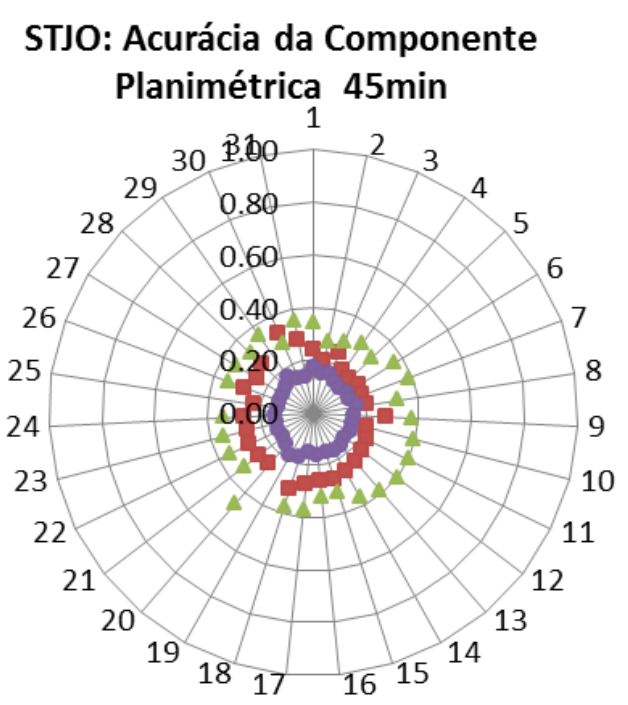

- GLONASS $\triangle$ GPS • GPS E GLONASS

\section{ONSA: Acurácia da Componente} Planimétrica $45 \mathrm{~min}$

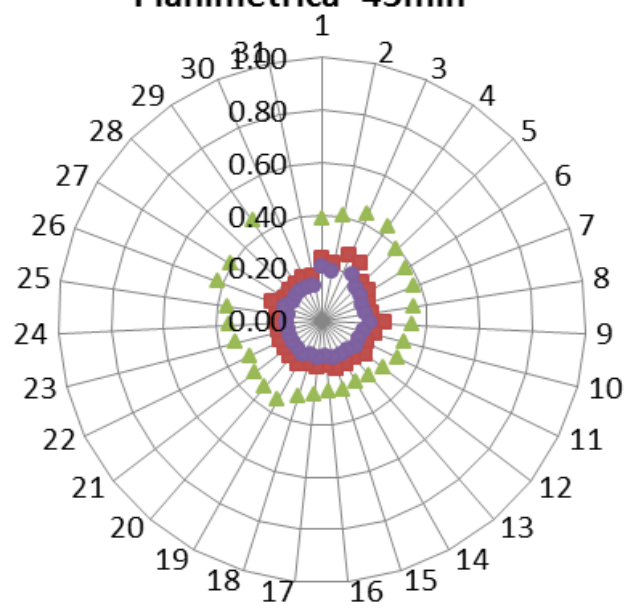

- GLONASS $\triangle$ GPS • GPS E GLONASS

KIRU: Acurácia da Componente Planimétrica $45 \mathrm{~min}$

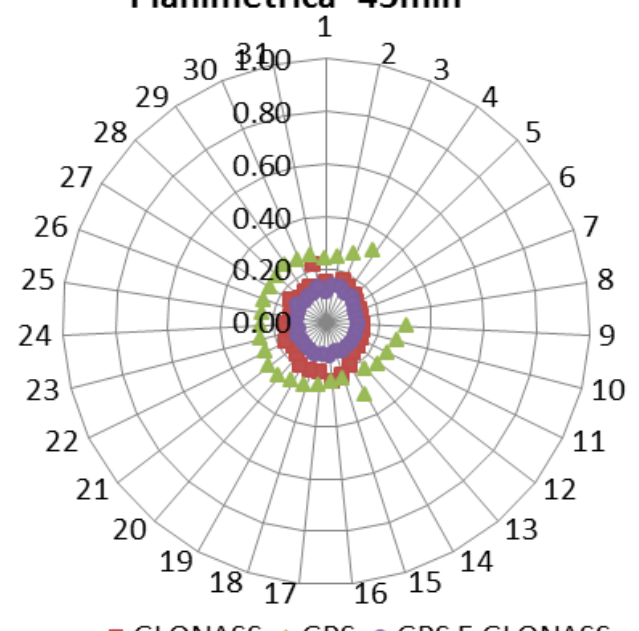

- GLONASS $\triangle$ GPS • GPS E GLONASS 
Figura 5 - Gráfico da variação temporal da acurácia planimétrica $(\mathrm{m})$ das estações STJO (lat: $48^{\circ}$ ) ONSA (lat: $57^{\circ}$ ) e KIRU (lat: $68^{\circ}$ ).
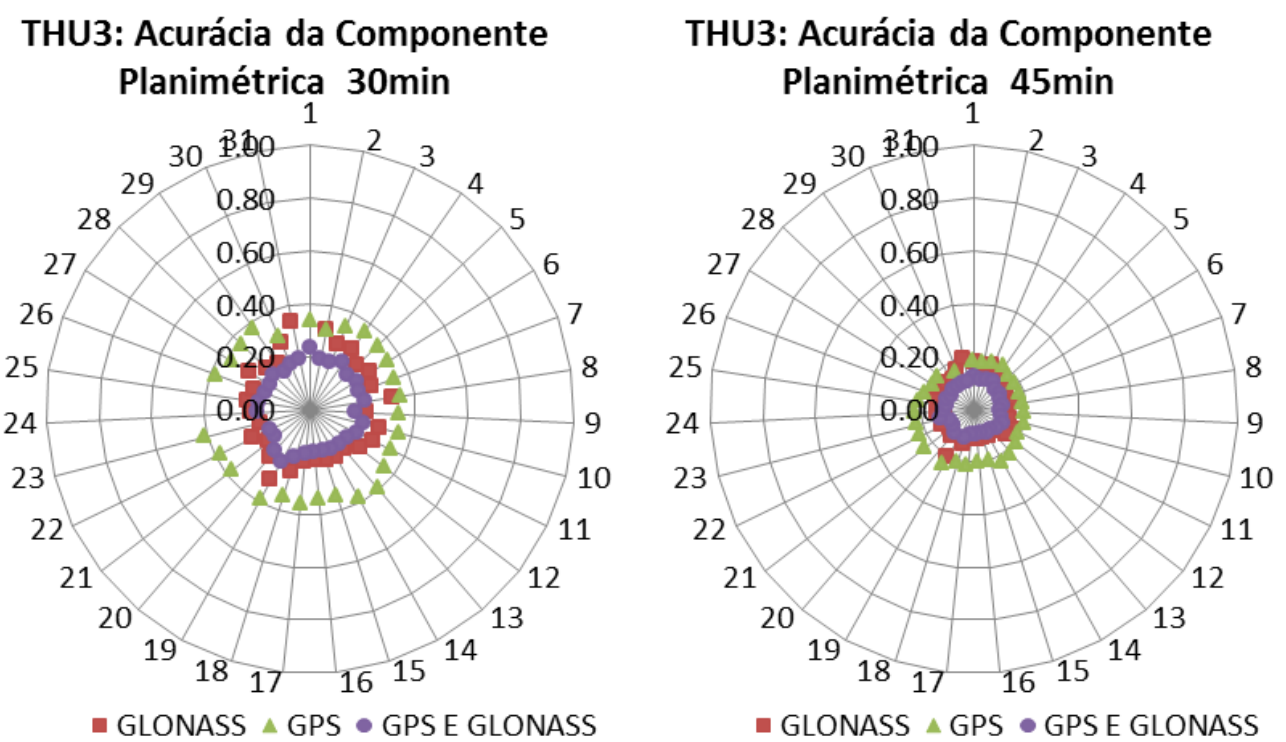

Figura 6 - Gráfico da variação temporal da acurácia planimétrica (m) da estação THU3 (lat: $\left.77^{\circ}\right)$.

Verifica-se que em todos os casos o PPP-GPS/GLONASS apresentou o melhor desempenho, com os menores valores de acurácia, sendo que foi o único processamento que alcançou acurácia centimétrica com 45 minutos de rastreio, na estação THU3. Destaca-se que nenhum valor de acurácia planimétrica ultrapassou o valor de $50 \mathrm{~cm}$ no PPP-GPS/GLONASS.

Nas estações PIMO e MAS1, com 30 minutos de rastreio, os valores de acurácia para os processamentos PPP-GLONASS e PPP-GPS, respectivamente, apresentam valores acima de 1m, que foram suprimidos dos gráficos para não perder o poder de comparação com as demais estações.

Interessante notar que na estação PIMO, para o PPP-GLONASS, a acurácia ultrapassou o valor de 1 metro (dia 03/08), e para o PPP-GPS, foram verificados vários outliers, correspondentes aos dias 18, 19, 20 e 21 de agosto. Contudo, no PPP-GPS/GLONASS nenhum valor de acurácia ultrapassou $30 \mathrm{~cm}$, e não apresentou nenhum outlier. Além disso, considerando o intervalo de 45 minutos para essa mesma estação, verifica-se que no PPP-GPS/GLONASS os valores de acurácia apresentam variação muito pequena, se comparado com os resultados obtidos no PPPGPS e PPP-GLONASS. Esse comportamento é similar em várias estações, porém em menor magnitude, o que evidencia a interoperabilidade entre o GPS e o GLONASS no PPP utilizando o serviço CSRS-PPP.

Para cada caso analisado (PPP-GLONASS, PPP-GPS e PPP-GPS/GLONASS), foram calculados 992 valores de acurácia (total de 2976). Para o PPP-GLONASS foram identificados 54 outleirs, no PPP-GPS 55 e no PPP-GPS/GLONASS 30 outliers. A detecção de outliers é realizada para cada gráfico gerado. Ou seja, neste caso, pode-se ter outliers com magnitude maior em determinado conjunto de dados e outliers com magnitudes menores referentes a outro conjunto de dados. Os outliers identificados no PPP-GPS/GLONASS, no geral, apresentam as menores magnitudes. Vale salientar também que um número menor de outliers detectados implica em resultados mais confiáveis, em função da menor variabilidade da acurácia calculada. 
Pode-se notar que com o aumento do intervalo de rastreio tem-se significativa melhora nos valores de acurácia, principalmente nas estações em que os valores estão mais dispersos e altos com 30 minutos, como nas estações HOB2, SUTM, CHPI, e PDEL.

Em todos os casos nota-se que a integração dos sistemas melhora a acurácia do posicionamento. Interessante notar as estações PIMO e MAS1 em particular, onde se pode ver claramente os benefícios da integração. Na estação PIMO o sistema GLONASS não apresenta um bom desempenho, com acurácia média muito alta. Na estação MAS1 acontece o inverso, o sistema GPS apresenta desempenho inferior aos demais processamentos. Porém, na integração, o desempenho é significativamente melhor, evidenciando novamente a interoperabilidade no PPPGPS/GLONASS.

\section{Considerações finais, conclusões e recomendações}

Diante dos resultados apresentados é notório o quanto a integração dos sistemas GPS e GLONASS melhora a acurácia planimétrica do posicionamento utilizando o método do PPP processados via CSRS-PPP, evidenciando a interoperabilidade entre o GPS e o GLONASS no PPP. Em alguns casos a acurácia foi significativamente melhor na integração, melhorando em torno de 2 decímetros o valor da acurácia.

Apesar do intervalo da estação BRAZ ser igual a 15 segundos, ao contrário das outras estações, que é igual a 30 segundos, não foi verificado alteração no tempo de convergência. Em outras palavras, as coordenadas estimadas época por época estabilizam praticamente no mesmo instante (para 15 e 30 segundos).

Ao analisar o desempenho do uso combinado dos sistemas com relação à latitude, pode-se verificar que a latitude pode não ter influência direta na qualidade do posicionamento, visto que os valores da acurácia das diferentes estações ficam bem próximos.

O mesmo não acontece quando se processa os sistemas individualmente, havendo variação com relação à latitude. De maneira geral, o sistema GLONASS apresentou resultados melhores em latitudes maiores, enquanto o sistema GPS se saiu melhor em latitudes menores. O que poderia levar à conclusão de que a inclinação orbital estaria influenciando diretamente sobre a qualidade. Entretanto ao analisar as estações em latitude próximas ao ângulo de inclinação de órbita do GPS (MAC1 e ONSA), onde se espera que o GPS apresente o melhor desempenho, nota-se que, embora em MAC1 o GPS tem melhor desempenho que o GLONASS, não se verifica isso em ONSA.

Embora possa haver influência do ângulo de inclinação da órbita dos sistemas na qualidade do posicionamento, essa influência não afeta significativamente a ponto de um sistema se sobressair ao outro por esse motivo. Portanto, diante dos resultados obtidos, não foi possível verificar a influência da latitude da estação na qualidade do posicionamento.

Algo importante de frisar é o bom desempenho do GLONASS com relação ao GPS, apresentando em 9, das 16 estações, acurácia planimétrica com valor menor em $100 \%$ dos intervalos de rastreio. E quando maior, os valores de acurácia são bem próximos.

A variação da acurácia com o intervalo de rastreio mostra que quanto maior o intervalo, melhor é o valor da acurácia. É importante frisar que o aumento do intervalo de rastreio não só melhora a acurácia, como pode minimizar algum efeito indesejável, como se observa, por exemplo, nas

Bol. Ciênc. Geod., sec. Artigos, Curitiba, v. 22, no2, p.264 - 281, abr - jun, 2016. 
estações CHPI e MAC1, em que os valores estão dispersos com 30 minutos, mas se agrupam significativamente com 45 minutos de rastreio.

Salienta-se que os resultados obtidos no serviço CSRS-PPP não necessariamente se repetirão para outros serviços.

Recomenda-se para trabalhos futuros que sejam realizados mais experimentos relacionados a integração entro o GPS e o GLONASS no PPP com a geração de séries temporais anuais. Com isso, será possível realizar uma análise sazonal da influência da integração entre o GPS e o GLONASS no PPP. Para isso, recomenda-se a utilização do programa GIPSY (GNSS-Inferred Positioning System and Orbit Analysis Simulation Software) para o processamento dos dados GNSS e o do programa R para análise estatística da série temporal.

Recomenda-se também que sejam realizados experimentos com o objetivo de avaliar o comportamento do tempo de convergência no caso da integração entre o GLONASS e o GPS no PPP em períodos de ocorrência de tempestades geomagnéticas, incluindo intervalos de tempo maiores no processamento dos dados GNSS.

\section{AGRADECIMENTOS}

A CAPES pelo apoio financeiro à pesquisa realizada e ao IGS pela disponibilidade gratuita dos dados.

\section{REFERÊNCIAS BIBLIOGRÁFICAS}

Bowring, B. R. 1976. "Transformation from Spatial to Geographical Coordinates." Survey Review 23 (181): 323-27.

Bruyninx, C., Altamimi, Z., Caporali, A., Kenyeres, A., Lidberg, M., Stangl, G., and Torres, J. A.. 2013. "Guidelines for EUREF Densifications." IAG Sub-Commission for the European Reference Frame.

Cai, C. 2009. "Precise Point Positioning using Dual-Frequency GPS and GLONASS Measurements." MSc diss., University of Calgary. http://www.ucalgary.ca/engo_webdocs/YG/09.20291_ChangshengCai.pdf.

Cai, C., and Gao, Y. 2007. "Precise Point Positioning Using Combined GPS and GLONASS Observations." Journal of Global Positioning Sistems 6 (1): 13-22.

Cai, C., and Gao, Y. 2013. "GLONASS-Based Precise Point Positioning and Performance Analysis." Advances in Space Research 51 (3). COSPAR: 514-24. doi:10.1016/j.asr.2012.08.004.

Farah, A. 2014. "Assessment Study of Static-PPP Convergence Behaviour Using Gps, Glonass and Mixed Gps/glonass Observations." Artificial Satellites 49 (1). doi:10.2478/arsa-2014-0005.

Ferrão, P. F. F. N. 2013. "Positioning with Combined GPS and GLONASS Observations." MSc diss., Técnico Lisboa.

Gibbons, G., Divis, D. A., and Gutierrez, P. 2013. "The GNSS Quartet: Harmonizing GPS, GLONASS, BeiDou and Galileo.” Inside GNSS 8 (1). http://www.insidegnss.com/node/3375. 
Grinter, T., and Roberts, C. 2011. "Precise Point Positioning: Where Are We Now?" In IGNSS Symposium 2011, 15-17. Sydney, Australia: University of New South Wales.

GMV, 2015. MagicGNSS. http://magicgnss.gmv.com/.

Hofmann-Wellenhof, B., Lichtenegger, H., and Wasle, E. 2008. GNSS - Global Navigation Satellite Systems: GPS, GLONASS, Galileo and More. Austria: SpringerWienNewYork.

IBGE (Instituto Brasileiro de Geografia e Estatística). 2013. Manual Do Usuário - Aplicativo Online IBGE-PPP. http://www.ibge.gov.br/home/geociencias/geodesia/ppp/manual_ppp.pdf .

Jerez, G. O., Alves, D. B. M., Souza, J. S., and Setti Junior, P. de T. 2014. "Análise do processamento combinado GPS/GLONASS no posicionamento por ponto e relativo com diferentes intervalos de tempo.” In XXVI Congresso Brasileiro de Cartografia V Congresso Brasileiro de Geoprocessamento XXV Exposicarta. http://www.cartografia.org.br/cbc/trabalhos/2/288/CT02-9_1403882339.pdf.

Lago, I. F. do, Ferreira, L. D. D., and Krueger, C. P. 2002. "GPS E GLONASS: Aspectos Teóricos E Aplicações Práticas.” Boletim de Ciências Geodésicas 8 (2): 37-53. http://ojs.c3sl.ufpr.br/ojs/index.php/bcg/article/viewArticle/1419.

Martin, I. 2013. "GNSS Precise Point Positioning: The enhancement with GLONASS". PhD diss., Newcastle University. https://theses.ncl.ac.uk/dspace/bitstream/10443/2192/1/Martin,\%20I.\%2013.pdf

Mikhail, E. M., and Ackermann, F.. 1976. Observations and Least Squares. New York: A DunDonnelley.

Monico, J. F. G. 2008. Posicionamento Pelo GNSS: Descrição, Fundamentos E Aplicações. 2nd ed. São Paulo: Editora UNESP.

R Core Team, A. 2014. "R: A Language and Environment for Statistical Computing." R Foundation for Statistical Computing. Vienna, Austria. http://www.r-project.org/.

Seeber, G. 2003. Satellite Geodesy. 2nd ed. Berlin, New York: Walter de Gruyter. doi:10.1515/9783110200089.

Torge, W. 2001. Geodesy. Berlin, New York: Walter de Gruyter.

UNB (University of New Brunswick). 2015. http://gaps.gge.unb.ca/.

Urlichich, Y., Subbotin, V., Stupak, G., Dvorkin,V., Povalyaev, A., Karutin, S., and Bakitko, R. 2011. "GLONASS Modernization." GPS World 22 (11): 34-39.

Urquhart, L.. 2009. "Atmospheric Pressure Loading and its Effects on Precise Point Positioning". Proceedings of the 22nd International Technical Meeting of The Satellite Division of the Institute of Navigation, 2009, pp. 658-667.

Vaz, J. A., Pissardini, R. de S., and Fonseca Junior, E. S. da. 2013. "Comparação da Cobertura e Acurácia entre os Sistemas GLONASS E GPS obtidas dos dados de observação de uma estação da Rede Brasileira de Monitoramento Contínuo.” Revista Brasileira de Cartografia 65 (3): 52939.

Whitehouse. 2004. U.S. Space-based positioning, navigation, and timing policy. https://www.whitehouse.gov/files/documents/ostp/Issues/FactSheetSPACE-

BASEDPOSITIONINGNAVIGATIONTIMING.pdf.

Recebido em junho de 2015.

Aceito em outubro de 2015. 